Folia Histórica del Nordeste, $\mathbf{N}^{\circ} 19$ (Resistencia, 2011) IIGHI, IH - CONICET, UNNE

\title{
REPRODUCCIÓN SOCIAL DEL CAMPESINADO EN MISIONES: PRÁCTICAS ECONÓMICAS HETEROGÉNEAS EN LA PRODUCCIÓN TABACALERA
}

\author{
Social Reproduction of Peasantry in Misiones: \\ Heterogeneous Economic Practices in Tobacco Production
}

María Carolina Diez

\section{Resumen}

A partir de la década de 1980 se consolida en Misiones un modelo tabacalero especializado, de agricultura bajo contrato con compañías multinacionales que exigen estrictas normativas de calidad y productividad, proceso acompañado por una continua tutela Estatal, que propicia la consolidación del Complejo Agro Industrial Tabacalero (CAIT) y sucesivas transformaciones en la estructura agraria.

El propósito central de este artículo es comprender estrategias de reproducción social desplegadas por productores vinculados al CAIT en Misiones, a partir del análisis de un conjunto de prácticas económicas heterogéneas en las esferas de producción y comercialización. En primer término, desde la revisión del material etnográfico relevado en la región del Alto Uruguay -nordeste de la provincia- se analizan las diferentes prácticas económicas, como arreglos y ayudas, formas de intercambios y acuerdos, del proceso productivo cultural y socialmente mediado. En segundo lugar, se identifican actores que realizan intermediaciones -denominadas desvíos- en la esfera de comercialización. Finalmente, se reflexiona sobre las formas de reproducción social de los productores, con especial atención en sus estrategias particulares y en las esferas de producción y circulación que configuran el modelo tabacalero.

$<$ Prácticas económicas $><$ Reproducción social $><$ Complejo Agroindustrial Tabacalero $><$ Misiones $>$

\begin{abstract}
Since the 1980s an especialized tobacco model has been consolidated, and the agriculture under contract with multinational companies -that require strict quality and productivity standards- has spread in Misiones. This process, accompanied by the continual tutelage of the State, has enabled transformations on the agrarian structure and the consolidation of the Agro Industrial Tobacco Complex (CAIT).

The main purpose of this paper is to understand the social reproduction strategies deployed by the agricultural producer envolved in the CAIT in Misiones, from the analysis of an heterogeneous group of economic practices in the production and commercialisation areas. Firstly, from the revision of empirical material (obtained from an ethnographic work that took place in an area called "Alto Uruguay"
\end{abstract}


Diez. Reproducción social del campesinado en la producción tabacalera en Misiones

in the Northeast of Misiones province), different economic practices will be analized: arrangements (arreglos) and aids (ayudas), exchange forms and agreements in the production process, culturally and socially mediated. Secondly, in the commercialisation area, those actors that carry out the mediation known as deviations (desvios) - will be identified. Finally, some reflections on the social reproduction of producers, emphasizing on the strategies based on the actors' experiences, production and circulation, and on the indirect articulation and configuration of a tabacco model will be presented.

$<$ Economic practices $><$ Social reproduction $><$ Agro-Industrial Tobacco Complex $>$

\section{Introducción $^{1}$}

Este artículo tiene como propósito central analizar el sentido que asumen diversas prácticas económicas en la producción tabacalera, en especial de un segmento de productores tabacaleros del Nordeste de Misiones, y el lugar que éstas tienen dentro del conjunto de estrategias de reproducción social. ${ }^{2}$

Retomamos y ampliamos una descripción inicial sobre la relación de estrecha subordinación entre agricultores e industria en la esfera de producción primaria (Diez, 2009), tomando en consideración las prácticas económicas -tanto en la producción como en la comercialización de la mercancía- analizadas en su heterogeneidad. Estas prácticas -que no necesariamente están sometidas al cálculo económico mercantil o sujetas a la intervención de dinero- asumen múltiples significados, en relación al conjunto de estrategias de reproducción social de los tabacaleros.

Diversos autores que analizan la conformación del Complejo Agroindustrial Tabacalero (CAIT). en la Argentina, (Aparicio, 2009; Baranger, 2007; Giménez, 2004; Gras, 2005; Re, 2008), señalan que se trata de una producción agrícola que se encuentra integrada verticalmente. El complejo tiene como denominador común la interconexión de distintas esferas: producción, comercialización -acopio, procesamiento- y consumo, que se relacionan de manera estrecha e involucran a una serie de actores, escenarios y procesos locales y extra locales (provincial, nacional y mundial) ${ }^{3}$.

\footnotetext{
${ }^{1}$ Una versión preliminar de este trabajo fue presentada en las VI Jornadas de Investigación en Antropología Social Sección de Antropología Social UBA, en Buenos Aires, del 3 al 6 de agosto de 2010. Quiero agradecer a Ilana Reck y las valiosas sugerencias para la versión final del presente artículo a Victoria Mailhos y Adriana Carísimo. Mabel, por qué las notas al pie no quedan alineadas bajo la primera letra del primer renglón???? O eso lo hacés vos en in-design???

${ }^{2}$ Desde el campo de la antropología económica la diversidad de prácticas económicas puede ser considerada un tema clásico. Para una síntesis sobre la discusión formalistas-sustantivistas ver Trinchero, 1992 y Balazote, 2007; para el debate en torno a la denominada racionalidad e irracionalidad en economía ver Godelier, 1970. Sobre la coexistencia de diversas prácticas económicas en donde la de mercado fue imponiéndose como dominante, ver el trabajo de Polanyi (1989) La gran transformación.

Estas cuestiones teóricas y metodológicas han cobrado una nueva relevancia luego de la denomina segunda Gran Transformación. El panorama de temas y problemas puede encontrarse detallado a modo de mapa conceptual en Buttel (2005), sobre todo respecto a la importancia de la nueva economía política agraria de fines del siglo XX.

${ }^{3}$ Las formas de articulación-subordinación de los productores agrícolas en el desarrollo del capitalismo,
} 
En el presente artículo se propone que las características del CAIT pueden ser analizadas a partir de la noción de articulación (Bartolomé, 1980), que refiere a una relación de conectividad entre actores sociales. Esta aproximación deja de lado nociones tales como cadena y eslabones utilizadas con frecuencia para describir el funcionamiento y las relaciones del CAIT y que subrayan dimensiones más o menos fijas y estables, exentas de cierta tensión y conflictividad. En este sentido, la articulación de productores al CAIT así como el denominado proceso de "industrialización del agro", pueden ser entendidos como el resultado de procesos históricos, sociales y culturales -muchas veces contradictorios- insertos en una compleja trama de relaciones.

El análisis de los cambios y transformaciones en las unidades productivas y en la configuración de la estructura agraria de las últimas tres décadas en el nordeste misionero representa un escenario oportuno para discutir la permanencia de formas campesinas de producción o de la llamada "agricultura familiar" frente al avance de formas plenamente capitalistas, así como la conformación de actores sociales (trabajadores rurales profesionalizados, temporales, etc.) y de procesos concretos que la mencionada tesis de industrialización en el agro no describe.

La producción tabacalera en Misiones se inicia con el proceso de consolidación de la agricultura industrial -principios del siglo XX-, formando parte de los cultivos de renta de importancia significativa. El tabaco acompañó la dinámica de poblamiento del territorio (en los procesos de colonización dirigida o tutelada por el estado y las empresas privadas) de pequeños productores generalmente sin capital que utilizaron este cultivo como un producto táctico y de espera. La variedad conocida como criolla o misionera, que proviene de tipos nativos ${ }^{4}$, alcanza, según Sonzogni (1983) su máximo crecimiento entre 1936 - 1946, proceso que se estabiliza luego de 1950. En este sentido el tabaco puede ser considerado como un cultivo fundacional.

A partir de la década de 1980 se inicia una reestructuración en el CAIT, que implicó la expansión de otra variedad de tabaco, fase denominada "boom del Burley" (Schiavoni, 1998). El boom ubicó al tabaco como una actividad agrícola dominante, en tanto que estructuró las actividades económicas en la región del Alto Uruguay -frontera con Brasil-. Una de las características de esta reestructuración fue la implantación del sistema de producción "bajo contrato" por parte de las empresas hegemónicas -Tabacos Norte y Cooperativa Tabacalera Misiones-. Los productores ingresaron a un circuito de comercialización regulado que les permitió acceder a un ingreso monetario y a una cobertura médica (obra social).

así como la integración vertical de los mismos, es discutido por numerosos teóricos clásicos (Marx; 1985; Lenin, 1973; Kaustki, 1970), populistas (Chayanov) y marxistas contemporáneos (Tepicht, 1980; Galeski 1977). Desde una perspectiva teórico- metodológica que articula las visiones precedentes ver Velho, 1976; Neves Pessanha, 1981, 1995.

${ }^{4}$ Dadas sus características: anual, utilización de pocas extensiones de tierra (1-2 has), mínima inversión de capital y limitados instrumentos de trabajo, permitía a los colonos un ingreso monetario rápido, mientras se implantaban especies perennes como la yerba mate que requería tiempo de espera no menor a tres años (Bartolomé, 2000, Schiavoni, 1998). 
Diez. Reproducción social del campesinado en la producción tabacalera en Misiones

Misiones es desde mediados de la década de 1990 la primera provincia productora de Burley de la Argentina, en términos de volúmenes producidos y exportados, cantidad de productores involucrados en la actividad, y crecimiento de la superficie implantada. ${ }^{5}$

Cabe señalar que el proceso de consolidación agroindustrial fue acompañado por la activa "tutela" del Estado -nacional y provincial- mediante la aplicación de las que se denominan políticas de federalismo fiscal, desde la instauración de la Ley Nacional de Tabaco (1967) y, especialmente, con la creación del Fondo Especial del Tabaco (FET), Ley $\mathrm{N}^{\circ} 19.800 / 72$. Desde ese entonces, el Estado ha operado como un verdadero auxiliar en la política expansiva tabacalera: propició la articulación de procesos locales y globales, facilitó la especialización regional en el cultivo del Burley y financió parte de la producción con lo que se conoce públicamente como el "retorno".

En términos analíticos, los tabacaleros de Misiones son un grupo heterogéneo compuesto mayoritariamente por productores que emplean fuerza de trabajo familiar, con pequeñas o medianas explotaciones cuyo promedio alcanza las 20 has., anotados ${ }^{7}$ para cultivar entre 30.000 y 60.000 plantas de Burley, que significan 2-3 has. del total de la explotación. Asimismo, existen otros agricultores con mayor nivel de capitalización que recurren a la contratación de mano de obra extra-doméstica. Los productores que componen la unidad de análisis de este trabajo son los del primer grupo, localmente denominados fracos, y que pertenecen a la segunda generación de tabacaleros. Son los protagonistas del proceso de profesionalización en el cultivo de Burley.

Según Schiavoni (2008) las trayectorias de estos productores del nordeste representan el pasaje de colono a plantador, y las condiciones de su reproducción social están íntimamente relacionadas a la producción tabacalera. En contraposición a los procesos sociales y económicos descritos en relación a la "agricultura colona" el "plantador tabacalero" podría ser caracterizado analíticamente como un tipo social campesino.

El sistema de producción bajo contrato implica que los productores firman papeles en la empresa para una campaña agrícola anual ${ }^{8}$; comprende la sesión de crédito

${ }_{5}^{5}$ La producción tabacalera en cifras: Volúmenes: Para la campaña 2006-2007 el total de tabaco del tipo Burley en kilos por Provincia: Misiones 32.334.246, Tucumán 4.222.906, Catamarca 850.286, Corrientes 50.597 (SAGPyA). Cantidad de productores de tabaco Burley: Según el Censo Tabacalero 2002, en Misiones fue de 14.122. Superficie en has: Pasando de 8.048 ha. en 1988 a 26.381 ha. en 2002, convirtiéndose en la principal productora a nivel nacional (Resultados Censo Nacional Agropecuario 2002).

${ }^{6}$ Se denomina retorno al sobreprecio que se abona directamente a los productores, creado por Ley 19.800 , que en su Art. 22, crea el Fondo Especial del Tabaco (FET), fijando un impuesto de 7\% del precio de venta al público de cada paquete a los consumidores de cigarrillos. Este impuesto es transferido de manera directa a los consumidores y concentrado por el Estado Federal. Posteriormente se redistribuye a las provincias productoras: Misiones, Corrientes, Salta, Jujuy y Tucumán.

7 Localmente un productor "anotado" es aquel que firmó un contrato o sesión de crédito con una de las empresas tabacaleras para una campaña anual.

${ }^{8}$ Éstos son meramente recibos consignando insumos a cuenta, es decir que tal contrato es la firma de papeles sobre la recepción de insumos e implica una deuda hasta el fin de la cosecha y entrega del 
para los insumos, y una determinada cantidad de plantas que se traduce en una cantidad de kilos a entregar (incluso en el caso de que el productor obtenga mayor cantidad de kilos la empresa no está obligada a comprar ese excedente). Para la producción de tabaco la empresa asigna y adelanta insumos, junto con una serie de recomendaciones al productor y controles de calidad y productividad, durante el ciclo anual del cultivo.

El proceso de trabajo del Burley -desde la semilla al armado de los fardos- se caracteriza por el empleo de fuerza de trabajo intensiva -gran cantidad de jornales y empleo de trabajo artesanal-, e involucra a los miembros de las unidades domésticas -incluyendo mujeres y niños- en especial en los períodos de cosecha y clasificación. A las múltiples exigencias de las empresas se suma el cumplimiento de las Buenas Prácticas Agrícolas 9 y el uso frecuente de agroquímicos -"lidiar con venenos"- comprendidos en el paquete tecnológico productivo.

El análisis que se presenta aquí está basado en una revisión del material empírico del trabajo de campo realizado en el Alto Uruguay entre los años 2004 y 2008. La zona está formada por pequeños productores tabacaleros especializados, tanto en relación de articulación directa con las empresas -mediante contratos- como en relaciones indirectas -"no anotados"- es decir sin registro formal. Este conjunto de relaciones se analiza con especial atención en el apartado sobre la diversidad de prácticas económicas.

La exposición del trabajo se realiza de la siguiente manera: en primer lugar, el análisis de las diferentes prácticas económicas de los productores de segunda generación tabacalera: arreglos y ayudas, entendidas como formas de intercambios y acuerdos de los tabacaleros durante el proceso productivo. El interés está puesto en resaltar las relaciones sociales y culturales que median esta producción. En segundo lugar, se identifica la esfera de comercialización denominada desvió. En tercer lugar, se describe cómo los actores mediadores -o intermediarios- operan en dicha esfera. Finalmente, se esbozan algunas consideraciones sobre el modelo tabacalero en Misiones.

\section{Producción tabacalera: una mirada desde los arreglos y las ayudas.}

La perspectiva adoptada para el análisis de las prácticas económicas, no sólo vincula la dimensión económica con la social y/o cultural, sino que entiende que la constitución de la dimensión económica se encuentra imbricada en la vida social -en el sentido que le otorgara Polanyi-, es decir, que no se halla delimitada como una esfera "económica" separada de otra "extraeconómica" tal como sostienen los teóricos de la economía política clásica. Los fenómenos económicos pueden ser entendidos como una totalidad y/o unidad.

producto. Antes quedaba una copia para el colono. Era un acta compromiso que la empresa tenía, y este año no dejó nada, ni un papel, refieren los productores.

${ }^{9}$ Las Buenas Prácticas Agrícolas (BPA) son un conjunto de principios, normas y recomendaciones técnicas "internacionales" aplicables a la producción, procesamiento y transporte de productos alimenticios y no alimenticios. Las BPA dan cuenta de procesos de internalización en la agricultura local y cómo las externalidades del mercado mundial operan en determinados contextos. 
Por otro lado, la existencia de una diversidad de formas económicas caracterizadas como campesinas -y autodenominadas como tales- en el desarrollo del modo de producción capitalista, abrió un debate ya clásico en antropología y sociología económica. Uno de los ejes de discusión fue el debate sobre la persistencia o la transformación del campesinado (caracterizado a partir de la organización de la producción en base doméstica) en otro actor social, devenido proletario o empresario agrícola. La unidad económica campesina, como objeto de análisis, desde Chayanov (1980) en adelante, permitió visualizar la superposición entre unidad de producción y unidad de consumo, y este rasgo distintivo no se desvanecería con el advenimiento de formas plenamente mercantiles. ${ }^{10}$ En este sentido, los estudios de antropología económica fueron muy prolíficos, de cara a la discusión con las posturas y estudios formales en economía. Con el surgimiento de la polémica entre el denominado populismo ruso (Chayanov, 1980) y el marxismo contemporáneo (Galeski, 1977) puede destacarse que una de las diferencias entre estos enfoques contrapuestos es la manera en que conciben la unidad de análisis. El primero toma exclusivamente la unidad familiar como sistema o modelo cerrado, donde unidad de producción y unidad de consumo se organizan y funcionan superpuestas, de allí su especificidad. El segundo, que intenta evitar una mirada parcial, circunscribe el análisis al sistema capitalista en el que las unidades económicas se encuentran inmersas (Diez-Kostlin, 2009).

La importancia de este conjunto de estudios radica en que señalan la estrecha relación entre las prácticas económicas y las relaciones sociales. Asimismo, como señala Buttel (2005) en la nueva economía política uno de los problemas a discutir y analizar continúa siendo el papel de la pequeña agricultura y la diversidad de formas económicas. La heterogeneidad como parte constitutiva en la consolidación de sistemas económicos globales.

Para comprender las prácticas de los productores tabacaleros vinculados al Complejo Agroindustrial se retoma además la vasta producción de estudios sociológicos sobre áreas tabacaleras que plantean la articulación vertical de las unidades productivas. Para el caso del CAI Tabacalero en diferentes regiones de Argentina: Gras, 2005; Aparicio, 2009; Re, 2008; para Misiones: Domínguez, 1995; Baranger, 2007; Schiavoni, 2008; y, sobre zonas tabacaleras del sur de Brasil: Paulilo, 1990; Guedes De Lima, 2007. Un aspecto central y común a todos ellos es que dan cuenta de procesos de diferenciación social en la estructura social agraria: tales como el surgimiento de categorías sociales y agentes políticos (gremios, cooperativas e instituciones). Otra de las características que resaltan estas investigaciones es que la agricultura bajo contrato combina procesos industriales con agrícolas, constituyendo un mercado laboral dinámico y conectado con procesos globales.

Empero, la descripción y análisis sobre los tabacaleros de Misiones presenta particularidades. En un trabajo precedente (Diez, 2009) se señala, que el proceso

${ }^{10}$ Las perspectivas que sostienen la persistencia de una economía campesina, organizada en base a criterios (jerarquía, edad, género, etc.) de la propia organización del parentesco ahondan sobre la dimensión de resistencia sobre el efecto de mercantilización de todas las esferas de la vida. 
productivo se combina con otras tareas agrícolas, ya que los productores no se dedican exclusivamente al cultivo de tabaco, sino que realizan otras actividades económicas vinculadas y destinadas al autoconsumo familiar (cría de ganado, huerta y cultivos anuales como el maíz y mandioca).

Como ya se ha mencionado, además de la relación de productores que están anotados -en relación directa con las empresas- existe un conjunto numeroso de productores que se encuentran en una relación indirecta como "no-anotados", y que continúa produciendo tabaco. ${ }^{11}$ En el caso de productores que fueron echados (expulsados de las empresas) pasan a ser reconocidos localmente como: plantadores por cuenta. Cabe señalar que estos productores se encuentran en una situación de mayor precariedad en lo relativo a las condiciones laborales. No sólo no tienen un contrato con las empresas tabacaleras, sino que no son incorporados en los censos y estadísticas oficiales, por ende plantan en escala reducida y con grandes dificultades. Generalmente esta situación de "estar por fuera" se resuelve apelando a otros integrantes de la familia: cuando se anota en la empresa a un familiar directo, la mujer, un hijo mayor o nuera. En los casos en que esto no sea posible, son los vecinos, compadres o parientes anotados quienes dispensan los insumos y, luego, entregan parte del tabaco a la empresa.

En los parágrafos siguientes profundizamos la descripción y el examen de intercambios y acuerdos en el proceso productivo y en la circulación -acopio y comercialización- del Burley, prácticas denominadas por los propios actores como arreglos y ayudas. Éstas son definidas en su conjunto como estrategias económicas que pueden ser entendidas como parte de las estrategias de reproducción social.

\subsection{Arreglos}

Analíticamente, se identifican y agrupan un conjunto de prácticas en la categoría local de arreglos vinculados a la producción tabacalera. Las dos modalidades de arreglos presentadas a continuación establecen formas intermediadas para aquellos productores que no mantienen un vínculo directo con una empresa y puedan cultivar Burley:

a) Arreglo entre un vecino anotado y un plantador que fue echado. Este caso fue relatado por el propio productor anotado, quien según sus propias palabras se encontraba en condiciones sociales y productivas de realizar esta ayuda para un vecino (obtuvo una buena cosecha y sólo tiene una hija que no está en edad escolar). Este productor entrevistado reside en una chacra de propiedad familiar, siendo el hijo menor, casado y -junto a su mujer e hija pequeña- moran en la misma chacra de su padre, que aún trabaja. Antes de prestar este arreglo hacía dos años había comprado un camión y junto a su hermano -también tabacalero y con una chacra contigua- comenzó a realizar fletes de tabaco en el momento de la entrega de Burley en las acopiadoras.

\footnotetext{
${ }^{11}$ Es atípico que un productor no haya pasado por la situación de anotado y es frecuente que quien es no anotado, sea porque mantiene una deuda con la empresa o haya sido simplemente echado. Aquí los motivos son varios, como una pelea con el instructor por haber transgredido alguna normativa de calidad como el uso de "semillas caseras", penalizadas.
} 
Diez. Reproducción social del campesinado en la producción tabacalera en Misiones

El término para referirse a la relación que establece con su vecino "no-anotado" es que ellos hicieron un trato. Este trato, se podría decir que mixtura elementos de lo que en la zona se denomina como ayuda, y que, por lo tanto, podría diferenciarse de aquello que es considerado como hacer negocio ${ }^{12}$. En sus palabras: -“...para ayudar, viste, yo le doy un poco de insumo, porque nosotros estamos anotados para más (kilos) y le di para que plante un poco, para ayudar". Este arreglo se realiza "de palabra" y no establece porcentajes. Consiste básicamente en entregar los insumos -que comprenden el conjunto de semillas, agroquímicos y a veces algún equipamiento como la mochila para fumigar- para que el productor que no puede anotarse plante en su tierra. Sólo en caso de que le sobre el cupo -cantidad de kilos establecido por la empresa- podría entregar el tabaco Burley en conjunto. En caso contrario, éste productor tendrá que buscar a alguien por fuera para que entregue y/o compre su producción.

- "Tiene el ejemplo del vecino, él hace tres años que viene mal. El primer año plantó y no conocía la tierra, no quería reconocer que donde plantó la tierra es pobre. Quedó con deuda y no pagó en la compañía (Tabacos Norte). Al año siguiente plantó y cosechó casi 2.000kgrs, ahí pagó la deuda del año anterior y solo le sobró \$300. El año pasado él no alcanzó de vuelta a pagar la deuda de los insumos. Entregó por tres años y solo ganó $\$ 300$ en la entrega de un año. Entonces ¿Para quién está trabajando? Y todavia le echaron en la empresa. No adelanta! ${ }^{13}$ Trabajar el año entero, llevar el tabaco y pagar los insumos y volver sin plata, sin nada. La tierra es pobre y como no le había sobrado plata del año anterior, él se obliga a salir a trabajar, a hacer changas 1-2 días o 3 por semanas para poder tener para vivir. Un poco que la tierra no le ayuda y otro poco la necesidad de salir a trabajar no le dejó atender el tabaco como siempre, como tendría que revisar las tareas. Y un poco las enfermedades (del tabaco)...y se quedó afuera de la Compañia. Porque el instructor (técnico que asignan a cada productor la empresa) le dijo que ya 3 años que no alcanza. Paga solo la cuenta." (Entrevista a Productor 37 años, 11/11/2005).

Cabe señalar que este acuerdo implica, por un lado, asumir el riesgo de una posible penalización en caso de ser descubierto. Pero, por otro lado, al tratarse de un

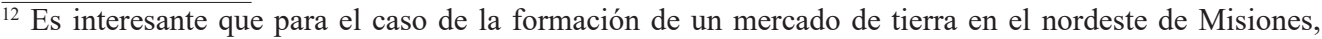
Schiavoni (2008) indica que las estrategias locales -el caso del brique- que son descritas y analizadas como formas e intercambios no institucionalizados y/o formalizados en los que se establece una transacción de palabra, median bienes -inmediatos o temporalmente diferidos- y sólo en algunas ocasiones interviene el dinero.

${ }^{13}$ No adelanta es una expresión en brasilero para significar que una situación no ayuda, o bien que no es beneficiosa.
} 
vecino se prioriza la relación de proximidad y el arreglo basado en una "evaluación amistosa" frente al cálculo económico del tipo costo-beneficio. Ello, al parecer, implica cierto grado de incomodidad: - "Yo... no es que le quiera sacar plata a él, sólo el insumo me tiene que pagar. Nosotros no arreglamos que tiene que ser tantos kilos de tabaco para mi". Los criterios que intervienen para describir y evaluar esta relación son morales donde quien ofrece el arreglo no debería parecer un "aprovechado" frente a un vecino "desfavorecido". La modalidad de este arreglo se diferenciaría de otras por estar más próxima a la ayuda y/o a la caridad. Menciones del tipo: - "Si él (vecino) fuera un sinvergüenza que fuera a desviar el tabaco yo no le iba a ayudar. Pero él es una buena persona y no tiene la culpa si le fue mal (en) la cosecha" La ayuda es para hacer un bien y solo se pide a cambio de que pague los insumos ..."Yo no me voy a ensuciar por dar una mano... Yo quiero que haga un buen trabajo".

Como ya se apuntó, los productores expulsados de las empresas quedan en una situación de mayor vulnerabilidad, debido a que no cuentan con beneficios sociales así como tampoco perciben el retorno proveniente del FET y, en muchos casos, pasan a trabajar fuera de la explotación realizando trabajos temporarios. En el acuerdo de un productor con un vecino, éste último se compromete a entregar una cantidad de kilos y en algunos casos implica algún tipo de contraprestación de trabajo o servicio, para cosechar o fumigar la plantación de quien ofrece el trato.

b) El caso de un "echo" de la compañía que arregla con un productor grande. El relato que se presenta corresponde a un productor de 42 años que reside en una tierra ocupada junto a su mujer y 10 hijos de entre los cuales los varones participan-ayudanen las tareas agrícolas y en especial con el Burley. Esta familia planta tabaco desde hace aproximadamente 25 años. El productor se presenta en los siguientes términos “...soy un echado de la empresa". Menciona estar fuera de todos los beneficios del tabaco - cobertura de Obra Social y retorno-, y recuenta las condiciones desfavorables y de vulnerabilidad en las que planta tabaco, además de reconocer que plantan porque es "lo único que $d a$ " un ingreso en dinero. Un productor grande, sub-financia a este productor echado mediante la entrega de los insumos necesarios para la campaña anual.

- "Me echaron el año pasado de la Compañía porque me fue muy mal. Quedé con deuda de \$4.500. Quiero pagar de a poco la deuda, tengo voluntad. Lo que pasa es que (al tabaco) le agarró la mushadera (peste o enfermedad) el año pasado". Agrega: -"No quería ni mirar el tabaco porque me hacía mal". Asegura que para este año tienen entre 80.000 y 100.000 plantas, han doblado la cantidad cultivada en relación a la campaña anterior- "Como estamos fuera (de la Compañía) primero tenemos que pagar la cuenta para tener Obra Social, primera cosa es pagar la cuenta para volver a entregar. (...) Ahora, vendo para particular. Voy a porcentaje con un colono que pide todo para mi (insumos) $y$ 
Diez. Reproducción social del campesinado en la producción tabacalera en Misiones

eso va a su nombre. Cuando es la época de entrega él saca un porcentaje del $10 \%$ de lo entregado. Sólo a la hora de la entrega cobra el precio que figura de los insumos". El negocio para el productor particular grande es que al entregar a su nombre tabaco que no plantó recibe un retorno. "Lo que hacen son kilos y les viene plata del retorno". (Registro de campo, 28/08/2004).

Aquí no se discutirá en profundidad este sistema agrícola mediante contrato y cómo éste implica un endeudamiento (Cfr. Diez, 2009), sin embargo, señalamos el sentido que asume esta relación económica para los productores luego de haber sido expulsados y contraído una deuda. Además de la pérdida económica, el estatus de productor cambia, éstos suelen ser clasificados como productores "relajados" o "descuidados", porque no trabajaron bien, e incluso se los convierte en una suerte de víctimas del poder arbitrario de las empresas: “...el tabaco era hermoso y me dieron mal promedio; ellos (la empresa) hacen lo que quieren, la cuenta se infló y el tabaco no".

Como señaló un productor: -"El que gana es el que tiene la balanza"14. Esta relación económica está vinculada a una posición de asimetría y subordinación que no se expresa únicamente en un plano de relaciones económicas, es por ello que la deuda contraída es acompañada por percepciones negativas sobre el comportamiento del propio productor.

\subsection{Ayudas}

Tal como señala Heredia (2003) la categoría trabajo asume diferentes significados para los propios actores. Refiere a un sistema clasificatorio complejo, y apunta a señalar el entramado de relaciones -prácticas y representaciones- que estos sujetos construyen en la vida cotidiana. En el caso que nos ocupa, la noción de ayuda permite identificar esta diversidad y explorar los sentidos locales de dicha categoría.

Ayuda remite, por un lado y en relación a la participación de los hijos, a las tareas que éstos realizan en la esfera doméstica tales como: buscar leña, alimentar animales, prender el fogón- cocina a leña y fazer servicio (conjunto de tareas domésticas: limpieza de la casa, lavado de ropa y preparación de alimentos diarios) y también a ayudar con el tabaco en los momentos de plantar y clasear $^{15}$. Por su parte, las mujeres consideran como ayuda a las actividades domésticas y las propiamente productivas: “...Las mujeres tenemos que ayudar con el tabaco porque si vos dependés solo del peón ¿Qué te sobra?”. Frecuentemente percibido de esa manera, el trabajo

\footnotetext{
${ }^{14}$ Interesante imagen porque la clasificación, es decir la selección del tabaco por más de 28 tipos y subtipos, la establece la empresa y los kilos de tabaco tienen un precio por clases. Entonces es frecuente que los productores hablen del promedio que sacaron por campaña anual.

${ }^{15}$ Plantar: refiere al transplante de los plantines o mudas de tabaco al rozado. Clasear: clasificación del tabaco, según normativas de las empresas.
} 
femenino tabacalero que realizan a la par de los hombres, se invisibiliza. Además, la denominación local ayuda, es extensible al trabajo temporario de changarines o peones, mano de obra contratada por tabacaleros que se vincula a tareas puntuales como la fumigación y carpida". ${ }^{16}$

Si bien el tabaco requiere de trabajo intensivo por parte de los miembros de la unidad doméstica y que por ello no puede descuidarse, en los momentos de mayor intensidad como son transplante, cosecha, construcción de un galpón, etc. se recurre a formas de mutuos intercambios o reciprocidad equilibrada (Sahlins, 1974) donde el intercambio instituye devoluciones de bienes y servicios proporcionados en un periodo de tiempo no muy largo. En palabras de un productor: -"Nos ayudamos, cada uno tiene lo suyo y cuida lo suyo y en caso de emergencia se ayuda. Como en épocas de trillar maíz. Si vienen, yo tengo ahi el tractor y la trilladera y vamos a trillar a la casa de algún vecino. Y es que ahora igual es muy poco lo que se planta y cuando es época del tabaco todos tienen su rozado. Pero igual siempre, trabajamos con un vecino" (Entrevista Productor 37 años, 11/11/05). Cabe señalar que para que la relación de reciprocidad perdure, debe mantenerse el flujo material entre las partes ${ }^{17}$.

En el nordeste misionero se observan sistemas de ayuda o contraprestaciones entre parientes y vecinos para la realización de una diversidad de actividades productivas. Entre ellas: terminar de plantar o cosechar tabaco, refacciones y construcción de galpones, carnear un animal, trillar maíz, etc. Muchas de estas actividades implican que un vecino se traslade llevando una máquina a una chacra vecina o bien que se reúna un grupo de productores en la chacra de aquel que tiene el espacio y la máquina. Cabe destacar que de todas ellas, la cosecha es la tarea que se realiza con frecuencia de manera colectiva y en jornadas grupales. Los miembros de una unidad productiva se trasladan a un rozado y luego de aquel jornal comparten un almuerzo en la casa donde se realizó el trabajo. Es interesante destacar que en el caso de no poder acudir personalmente, un pariente puede ayudar enviando a un peón que se encuentra realizando tareas en su propia chacra para hacer algún trabajo puntual en la del vecino.

Los sistemas habituales de ayuda arriba descritos son el cambio de día y el ayutorio también denominado pucherón. El primero puede ser cambio de trabajo por préstamos de un tractor para preparar un rozado, etc. Generalmente el segundo implica la reunión de un grupo familiar o de vecinos que realizan una tarea conjunta durante un jornal Es interesante destacar que en ambos casos se recurre a esta ayuda para evitar el pago de salarios. También en situaciones consideradas críticas como la enfermedad

\footnotetext{
${ }^{16}$ La resistencia a reconocer este trabajo de peones, tiene varios aspectos, uno de ellos es que el colono es quien sabe trabajar con el tabaco y estos trabajadores no realizan tareas "transferibles", o bien porque es un gasto que simplemente prefieren evitar.

${ }^{17}$ Existen distintos tipos de reciprocidades que Mauss denomina "economía de las donaciones", tratándose todas ellas de formas de intercambios. La reciprocidad generalizada comprende las transacciones simultáneas o "don puro". En estos casos la obligación de devolver está apenas esbozada, no hay un cálculo de las deudas, ni una estipulación del momento de la devolución. Otro caso es la reciprocidad negativa, donde la relación es más impersonal que las presentadas anteriormente y tiene la forma de un trueque o regateo (En: Sahlins, 1974).
} 
de un pariente o vecino, accidentes e internaciones, se realizan los ayutorios. En estos últimos casos también se identifican ayudas vinculadas a tareas domésticas, como el cuidado de los hijos y/o trabajos de la casa por parte de un pariente, también en casos de maternidad o viajes para la realización de estudios médicos, etc.

Dentro del conjunto de intercambios señalados en la región, Schiavoni (2008) analiza el brique o negocio amistoso como la acción de cambio de bienes sin la intervención de dinero. El brique se realiza sobre todo con animales, o préstamos para reproducción del ganado. La autora compara y caracteriza diversas formas de circulación e intercambios de bienes -trueque, don, e intercambios mercantiles- en el nordeste de Misiones, con las que el brique coexiste y se diferencia. En sus términos, constituye un tipo de transacción caracterizada por su informalidad y se establece entre personas de un mismo rango -parientes, conocidos, amigos y vecinos- entre quienes se intercambian diversos bienes -tierra, animales, artículos domésticos-. Conforma una modalidad de compra que se traduce en arreglos autorizados, no vinculados a prácticas de reciprocidad o amistad. Cabe señalar que si bien no existe la intervención de dinero, se lo utiliza como referencia. Las equivalencias se establecen en términos amistosos, incluyendo el componente de la ocasión -momento oportuno- en la formación de valor.

Por último, otras prácticas identificadas como ayudas recíprocas entre parientes y vecinos son las que implican la circulación de herramientas (trilladora, motosierra); otras, en cambio, conciernen a la producción de tabaco: un productor puede pasar kilos a otro, cuando éste no ha tenido una buena cosecha, para así poder completar el mínimo de entrega. También en el caso inverso, cuando un productor sobrepasa el tope máximo permitido, suele repartir entre parientes cercanos o compadres. Luego de la entrega -en ambos casos- el retorno es repartido y no se realizan prácticas de retención en dinero o cobro de porcentajes como ocurriría en casos en donde la distancia social es mayor.

\section{EI desvío}

Una modalidad específica de intercambio en la producción tabacalera se denomina desvío. Se trata de una forma de intermediación en donde un bien -el tabacopasa por un circuito o canal de comercialización previo antes de llegar a la empresa tabacalera. Un productor decide vender parte o la totalidad de la producción de tabaco a un mediador que compra -que puede acopiar el producto o directamente entregar el tabaco-, dejando de esta manera la deuda o parte de ella en la compañía ${ }^{18}$.

Desvío, alude pues a la imagen de una bifurcación en un cauce que llega a un mismo destino. Un tabacalero al hablar de este tema se refirió metafóricamente al "río que desvía su cauce" que aparenta transformarse, sin embargo sus aguas llegan al mismo destino. El Burley, en vez de confluir en la "boca de acopio", va por otras manos, se desvía a otras redes, ya sea de un productor local o un comprador de Brasil.

\footnotetext{
${ }^{18}$ En contraposición a lo que ocurre en la provincia Argentina de Jujuy donde el productor puede "elegir" el comprador o bien "ejercer presión", un productor que "se anota" en Misiones en una empresa debería sólo vender a la empresa.
} 
El desvío, al igual que el caso arriba mencionado del brique, nos señala una heterogeneidad de prácticas. La integración vertical de productores al CAIT se complejiza, al aparecer otros actores y canales de comercialización. El desvío y con ello la producción de tabaco es parte de un conjunto de transacciones económicas, como ilustra una productora ( 35 años) al hablarnos sobre la intervención del desvio en intercambios locales.

Ella y su marido compraron machimbre para la construcción de su nueva casa de "material", como les sobró un lote de madera y aun no habían terminado de saldar el pago en el aserradero decidieron cambiarlo. El señor que toma el machimbre decide vender una vaca para pagar el lote de madera, pero la persona que compra la vaca necesitaba vender primero su tabaco. Como aún no habian fijado el precio del Burley y por lo tanto no se había abierto el acopio, entonces parte del tabaco sería desviado para que luego de pagar el tabaco puedan pagar la vaca y finalmente la madera. Al momento de este relato el círculo no se había cerrado con la intervención de dinero y la productora se refería con tranquilidad sobre este "pase de manos" primando un elemento de confianza por sobre otras prácticas, incluyendo al aserradero y el machimbre adeudado. (Notas de campo, $12 / 09 / 2008)$

Según Schiavoni (2008), las sociedades mercantilizadas con escasa institucionalización económica no pueden ser pensadas sólo en términos de intercambios domésticos y tampoco totalmente mercantiles. Es decir que “(...) en un contexto de capitalismo actual, caracterizado por una economía desregulada, persisten intercambios no basados en el dinero y/o cálculo, o en otras palabras, que no descansan en sistemas uniformes de equivalencias" (2008:151).

Es interesante entender que cuando se desvía la producción -total o parcialmentese asocia este acto a una transacción mercantil -venta-, en aparente contraposición a la nominación de entrega cuando la transacción es con la compañía. Generalmente, esta práctica es considerada como una alternativa para tener dinero más rápido en el caso de necesitarlo con premura y no poder esperar el turno; tal vez porque "la cuenta es más alta" que lo que ganarán o porque el cambio con Brasil conviene. El desvío se realiza a veces de manera deliberada porque saben con anticipación que luego de pagar los insumos no ganarán nada, y aparece como una estrategia factible y la única posibilidad -aunque limitada- de sacar un poco más de lo que la empresa establece como precio. Una estrategia es también vender la mitad de la producción, porque existe un margen de deuda en la empresa que se puede dejar de un año para otro.

Todo ello evidencia una lucha de fuerzas existente en el campo de producción tabacalera, y es tenida en cuenta por muchos productores como una opción para el 
Diez. Reproducción social del campesinado en la producción tabacalera en Misiones

ejercicio de cierta presión. En relación a las empresas y sus directivas, los productores gozan de una autonomía relativa en el sentido en que están insertos en un campo social con reglas que no pueden alterar en su totalidad y que los determinan en cursos de acción, sin embargo son capaces de -en su propia dinámica y términos- retraducir las demandas y coacciones externas en nuevas prácticas capaces de interpelar al orden estatuido.

La advertencia de una posible demanda contra el productor funciona como una amenaza al igual que otras prácticas que la empresa sanciona. Aquello que se conoce como "la deuda en la empresa" es tolerada en algunos casos y depende del instructor, luego de tres años la empresa descarta productores y selecciona a los que permanecen anotados (Schiavoni, 200, Diez, 2009). Esta tendencia a reforzar la idea y práctica de la penalización sobre las condiciones de entrega del tabaco ha generado y aún genera un efecto de disciplinamiento sobre los productores y trabajadores técnicos como los instructores.

También es frecuente observar cómo este discurso de penalización aparece en los medios de comunicación con notas tituladas como: "Tabaco: Denuncian la presencia de acopiadores brasileños en territorio argentino" 19 en donde exponen hallazgos de tabaco y las posibles penas para los productores que desvíen el producto, asociando el desvío con ilegalidad y contrabando, realizado por los llamados "acopiadores brasileños".

En otro lugar (Diez, 2009) reflexiona sobre los desvíos como prácticas de resistencia, una acción de presión y estrategia para que se mantenga el precio porque de esa manera las empresas pierden plata (en los casos en que los mismos productores desviaron a productores próximos). Tal como lo señala Ferrero (2005) esta situación puede ser vista sobre todo a partir de la devaluación. Sin embargo, además de la situación cambiaria con Brasil, y dado que los desvíos se dan en un contexto de protestas -2007 y 2008- como los cortes de ruta y lucha por el establecimiento del precio de acopio, esa situación hizo que muchos tabacaleros se sientan pichados ${ }^{20}$ y cansados razón por la que muchos tabacaleros decidieran desviar a cambio de un mejor precio ofrecido. Se agrega al descontento la situación de conflicto respecto a los dirigentes de la APTM (Asociación de Plantadores de Tabaco Misiones) y del otro gremio CaTaM (Cámara del Tabaco de Misiones).Las organizaciones que representan a los productores tabacaleros, adjetivados como pequeños y grandes, se caracterizan por mantener un estilo jerarquizado y de limitada participación de los productores. Esto muestra una estructura precaria de representación de los intereses de los productores. En efecto, los gremios tabacaleros gestionan la integración subordinada de los productores a la agroindustria. (Schiavoni, 2008).

\footnotetext{
${ }^{19}$ Fuente: Diario Misiones Online 28/03/2008 y 20/08/2008.

${ }^{20}$ Pichado: Con enojo.
} 


\section{Mediadores en la comercialización del Burley}

Como se ha señalado en la producción tabacalera y en especial desde los años 2006-2007 emergen diversos agentes especializándose en la intermediación en la esfera primaria de producción y circulación del tabaco. Tanto los productores como los denominados chiveros realizan un pase de manos. Los últimos funcionan en la práctica como acopiadores locales o intermediarios. Generalmente se trata de productores que se han capitalizado -con la compra de un camión, el armado de un galpón, etc.- y se posicionan como mediadores, gozan de un reconocimiento local y -según los productores, la empresa y el instructor-tienen conocimiento de la situación, sobre todo para plantar una cantidad superior a la que el productor realmente produce.

Chivear es reconocido en la zona del alto Uruguay como un trabajo autónomo y especializado, una práctica extensiva. Y chivero, refiere a la persona que lleva y trae mercaderías de un lado a otro de la frontera. "Acá todos son chiveros, yo también", me describió una productora. Al igual que las paseras en la frontera Paraguay/ Argentina y también recientemente los paquitos especializados en pasar "de una lado a otro" productos de electrónica. Sin embargo chiveros también hace referencia a los compradores de tabaco que generalmente cruzan la frontera (Brasil) pero no se dedican a ello exclusivamente.

La diversidad de actores involucrados en la compra-venta de tabaco, sean o no productores, da cuenta de una complejidad que implica por un lado repensar la denominada articulación vertical de productores a la agroindustria y por otro lado las lógicas de su funcionamiento y las transformaciones y cambios generados en el tiempo y espacios, así como en las relaciones sociales. Los chiveros aparecen como una opción de venta ya que cuentan con un grado importante de organización, estrategias definidas y con el equipamiento necesario para desarrollar la actividad. Los compradores de tabaco llegan a las chacras antes de la fecha de entrega, cuando los fardos ya están preparados o en el proceso de clasificación del tabaco.

"No se trata de improvisados, ellos (los chiveros) están bien organizados, llegan a las chacras -este año ofrecían buen precio- y mucha gente se puso de acuerdo para desviar todo el tabaco, algunos igual siguen plantando porque hay otros productores grandes que les dan insumos o se anota la mujer o plantan casero (se refiere al empleo de semilla prohibida o penalizada) o arreglan con otro a medias o plantan para otro. Nosotros no desviamos porque necesitamos la obra social". (Notas de campo, 11/09/2008).

Además del chiveo de aquellos que sólo compran y venden, se puede identificar a una diversidad de actores en la esfera de comercialización denominada como desvíos: (a) los que plantan y compran (b) grandes productores con convenio.

Los primeros (a) son tabacaleros que figuran como plantadores anotados en la empresa y compran tabaco generalmente hasta cubrir el cupo establecido por 
las empresas. Se diferencian de los denominados grandes compradores. Se trata de productores en la que su actividad principal es plantar Burley y comprar tabaco. La trayectoria de estos productores es ascendente, registran una cierta capitalización -compra de un acoplado para la cosecha, cambio de automóvil, lotes de más de 30 has., compra de un camión, etc.- y con ello el acceso a la esfera de la circulación del tabaco. Las acopiadoras no abonan ni aseguran el traslado hasta la boca de acopio, lugar donde se entregan los fardos, es decir el tabaco preparado. Los que son plantadores y compran tabaco, al igual que quienes realizan arreglos se ven amenazados por una posible expulsión del circuito formal. Por su parte, los productores diferencian entre los que son grandes y pequeños compradores, los primeros se definen como plantadores. Para una familia de productores asumir esta nueva actividad significa trabajo adicional como la revisión del tabaco comprado, porque no conocen a los productores ni su forma de trabajo y quieren evitar cualquier tipo de sanción por parte de la empresa. Esta tarea adicional para el plantador genera que éste contrate fuerza de trabajo de peones con mayor frecuencia o a veces para todo el año agrícola.

Por otro lado están los grandes compradores (b) que se diferencian de los que plantan y compran por el tipo de trabajo que realizan, por los volúmenes que manejan, compradores de más de 100 mil kilos, mediante acuerdos previos, no se trata entonces de un tabaco únicamente desviado. Aunque se habla de que el tabaco que la empresa rechaza en la boca de acopio vuelve en manos de un mediador como los grandes que compran.

\section{Consideraciones finales}

Cada una de las situaciones que se describen en este trabajo intenta avanzar en la caracterización de las condiciones de trabajo y de reproducción social de este conjunto de agricultores, poniendo el foco principalmente en la emergencia de actores usualmente no visibilizados y que también forman parte de este campo de relaciones. Como también se mencionó, los "no anotados" conforman la parte negada de la integración vertical. Paradójicamente, a pesar de ser negados, todos los actores de la cadena son conscientes de su existencia. De hecho, según algunos informantes, la empresa conocería estas situaciones informales y también sacaría un rédito de ellas.

Puede sostenerse que las prácticas económicas en la producción tabacalera son heterogéneas y se encuentran imbricadas en las relaciones sociales y culturales. Estar integrado verticalmente al CAIT no representa una esfera separada ni autónoma de la vida cotidiana para cierto segmento de productores, que en muchos casos sí han atravesado un proceso de especialización o profesionalización.

Como se vio, la relación de articulación con el CAIT impone a los tabacaleros márgenes de acción estrechos -por las normativas y controles que estipulan las empresas (tipos del producto, calidad, cantidades, formas de trabajo, etc.)- sin embargo, la experiencia de tres décadas en la plantación intensiva del Burley, hace que los propios 
productores desplieguen estrategias en base a su formación como plantadores, resultado de la experiencia en su trayectoria como segunda generación tabacalera.

Los productores no son receptores pasivos de las directivas de las empresas, y tal como lo señala Castiglioni (2007) teniendo en cuenta las situaciones descriptas, es posible afirmar que, directa o indirectamente, los productores ponen en marcha estrategias para contrarrestar de alguna manera la presión de las compañías y la dependencia para con ellas. Este es el caso de las ayudas y arreglos. Además, se identifican, en el conjunto de prácticas heterogéneas llevadas a cabo por productores en pos de su reproducción social, diferentes significados de lo que es trabajo/ayuda y cómo se construyen sentidos y relacionan con vínculos de parentesco y de vecindad.

Es posible afirmar que las formas de relación con la empresa propiciaron nuevas diferenciaciones internas en el conjunto de productores genéricamente denominados tabacaleros. Las trayectorias de capitalización y el surgimiento de algunos mediadores -en la esfera de circulación- ligados al compás del tabaco, no corresponden a una lógica externa, sino que la misma tendencia a la expulsión y concentración privilegia este funcionamiento.

Estas diferenciaciones internas en el conjunto de los productores tabacaleros y en relación a la dinámica de funcionamiento de la Agroindustria en su fase primaria -teniendo en cuenta su relación con la empresa, directa o indirecta, y según las modalidades de acuerdos que propicia para quienes están fuera de ella- hace (re)pensar la propia categoría de plantador, es decir, asociada a un productor que mantiene una relación económica y legal con las empresas. Por lo tanto una parte (por cuenta, no anotados) queda al margen de las cifras oficiales, estadísticas y los registros que la misma producción tabacalera ha generado. A esta exclusión Bourdieu (1996) denomina "unificación teórica y cognitiva" como parte del proceso de homogeneización construida por el estado en su ejercicio de la nominación burocrática. Además así como los productores expulsados no son registrados mediante el censo anual de plantadores, las mujeres tabacaleras, los peones rurales vinculados al cultivo del Burley son invisibilizados.

Las estrategias de los tabacaleros no deben ser entendidas como simples transacciones económicas, una opción teórico-metodológica es seguir el recorrido de sentido que le otorgan los propios actores a sus prácticas y los términos en que se realizan distintas intermediaciones entre productores y otros agentes sociales. La etnografía de estos procesos en su funcionamiento puede producir información para entender el proceso histórico y social, puesto que desde la representación construida en los registros no se da cuenta de la diversidad de prácticas económicas.

\section{Referencias Bibliográficas}

Aparicio, Susana. 2009. Tabaco, mercado de trabajo y cultura en Jujuy. (14 de Junio de 2009): http://www.srt.gov.ar/publicaciones/Tabaco/Tabaco.pdf. 
Diez. Reproducción social del campesinado en la producción tabacalera en Misiones

Balazote, Alejandro. 2007. Antropología económica y Economía Política. Centro de Estudios Avanzados, Universidad Nacional de Córdoba.

Baranger, Denis, et al. 2007. Tabaco y agrotóxicos. Un estudio sobre productores de Misiones. Posadas, Editorial Universitaria de Misiones.

Bartolome, Leopoldo. 1980. "Sobre el concepto de articulación social". En: Desarrollo Económico Vol. $20 \mathrm{~N}^{\mathrm{o}}$ 78, Jul-sep, Buenos Aires.

Bartolome, Leopoldo. 2000. Los colonos de Apóstoles: estrategias adaptativas y etnicidad en una colonia eslava en Misiones. Posadas. Editorial Universitaria.

Bourdieu, Pierre. 1996. "Espíritu de estado: génesis y estructura del campo burocrático". En: Razones prácticas sobre la teoría de la acción. Campinas, Editorial Papirus.

Buttel. 2005. "Algunas reflexiones sobre la economía política agraria de fines del siglo XX". En: Barbosa Cavalcanti, J. y G. Neiman. (comp.) Acerca de la globalización en la agricultura Territorios, empresas y desarrollo local en América Latina. Buenos Aires, Editorial Ciccus.

Chayanov, A V. 1980. "Sobre a teoría dos sistemas econômicos não capitalistas". En: Graziano Da Silva, J y V.Stolcke. A questão agrária. São Paulo. Editora Brasiliense.

Diez, Carolina. 2009. "O fumo não paga nosso sofrimento” Pequeños productores y Agroindustria: Una etnografia en Colonia Aurora, Misiones. Tesis de Licenciatura en Antropología social FHyCS UNaM .

Diez, Carolina y Kostlin, Laura. 2009. "Persistencia y cambio del campesinado. Un abordaje crítico a 'La Morada de la Vida' desde el marxismo contemporáneo" En: Revista de estudios rurales Mundo Agrario, vol. 10, n 19 . Centro de Estudios Histórico Rurales. Facultad de Humanidades y Ciencias de la Educación. Universidad Nacional de La Plata. (20 de Marzo de 2010) http://www.mundoagrario.unlp.edu.ar

Dominguez, Caroline. 1995. Territoire, Produit et Conventions. La dynamique tabacote sur le front pionnier de la province argentine de Misiones. A la croisee de plusieurs mondes... These Universite Toulouse Le Mirail. Formation.

Ferrero, Brián G. 2005. Estudio de la gestión territorial y de los recursos naturales, de la población rural del Área de Influencia de la Reserva de Biosfera Yabotí, Argentina.

Programa Man And Biosphera UNESCO. (03 de Octubre de 2008) http://www.unesco.org.uy/ mab/documentospdf/brianferrero-becamab.pdf

Galeski, Boguslaw. 1977. Sociología del campesinado. Barcelona, Ediciones Península.

Giménez, María L. 2004. Trayectoria y organización productiva de sectores medios de productores medios de tabacaleros en la provincia de Salta. Tesis de maestría en Ciencias Sociales del Trabajo, Centro de estudios Avanzados UBA, Buenos. Aires.

Gras, Carla. 2005. Entendiendo el agro. Trayectorias sociales y reestructuración productiva en el nordeste argentino. BIBLOS, Buenos Aires.

Guedes de Lima, Ronaldo. 2007. "Desenvolvimento e relações de trabalho na fumicultura sulbrasileira". En: Sociologias, Porto Alegre, ano 9, n 18, jul./dez. p. 190-225.

Heredia, Beatriz M. 2003. La morada de la vida. Trabajo familiar de pequeños productores del nordeste de Brasil. Buenos Aires, La Colmena.

Kautski, Karl. 1970. “El campesino y la industria”. En: La cuestión agraria. Paris, Ruido Iberico. 
Lenin, Vladimir. 1973. El desarrollo del capitalismo en Rusia. Moscú, Editorial Progreso.

Marx, Karl. 1985. El Capital. México: Siglo XXI.

Neves Pesanha, Delma. 1981. Lavradores e pequenos produtores de cana. Estudio de las formas de subordinacao dos pequenos productores ao capital. Sao Paulo: ZAHAR.

Neves Pesanha, Delma. 1995 “Agricultura familiar: questões metodológicas”. Reforma Agrária. Vol. 25. Número 2-3. mai-dez. pp. 21-36.

Paulilo, Maria Ignez S. 1990. Produtor e agroindústria consensos e dissensos: o caso de Santa Catarina. Florianópolis, Editorial UFSC.

Polanyi, Kartl. 1992. La gran transformación: los orígenes políticos y económicos de nuestro tiempo. México, D.F., FCE.

Re, Daniel. 2007. "La movilidad social de los productores tabacaleros en la provincia de Jujuy". Instituto de Investigaciones Gino Germani. IV Jornadas de jóvenes investigadores. Buenos Aires 19, 20 y 21 de septiembre (08 de Octubre de 2008) http://www.iigg.fsoc. uba.an

Sahlins, Marschal. 1984. La economía de la edad de piedra. Madrid, Editorial Akal.

Schiavoni, Gabriela. 1998. Colonos y ocupantes: parentesco, reciprocidad y diferenciación social en la frontera agraria de Misiones, Posadas, Editorial Universitaria de Misiones.

Schiavoni, Gabriela (comp.). 2008. Campesinos y agricultores familiares. La cuestión agraria en Misiones a fines del siglo XX. Buenos Aires, Editorial CICCUS.

Tepicht, Jerzy. 1973. Marxisme et Agriculture: Le Paysan Polonais. Paris, Armand Colin.

Trinchero, Hugo. (comp)..1992. Antropoloía Económica II. Conceptos fundamentales, Buenos Aires, CEAK.

Velho, Otávio G. 1976. Capitalismo autoritário e campesinato. Sao Paulo, DIFEL. 